\title{
Kararlı angina pektoris
}

\section{Stable angina pectoris}

\section{Korhan Soylu}

Ondokuz Mayıs Üniversitesi, Tıp Fakültesi, Kardiyoloji Anabilim Dall, Samsun, Türkiye

\begin{tabular}{|c|c|}
\hline MAKALE I & GÍLERİ \\
\hline Makale geçı & \\
\hline Geliş tarihi & : 30 / 06 / 2011 \\
\hline Kabul tarihi & : 05 / 07 / 2011 \\
\hline
\end{tabular}

\section{Yazışma Adresi:}

Korhan Soylu

Ondokuz Mayıs Üniversitesi,

Tıp Fakültesi,

Kardiyoloji Anabilim Dalı,

Samsun, Türkiye

e-posta: korhansoylu@yahoo.com

\section{Anahtar Kelimeler:}

Kararlı angina

Angina

Göğüs ağrısı

Koroner arter hastalığ

Efor anginası

\section{Keywords:}

Stable angina

Angina

Chest pain

Coronary artery disease

Exertional angina

\section{ÖZET}

Koroner arter hastalığı tüm dünyada yaygın bir ölüm nedenidir. Kararlı angina pektoris göğüste veya çevresinde efor ile oluşan bir rahatsızlıktır. Bu derleme kronik stabil anjinanın medikal ve invasif tedavi seçeneklerini ve yeni stratejileri ortaya koymayı amaçlamıştır. Tedavinin amacı yaşam kalitesini iyileştirmek, kardiyovasküler olay ve ölümleri azaltmaktır. İdeal tedavi seçiminin belirlenebilmesi için risk derecelendirmesi yapılması gerekir. Bu derecelendirme hiyerarşisi: Klinik değerlendirme, stres testleri, sol ventrikül fonksiyonu ve koroner anjiyografi şeklinde sıralanabilir. J. Exp. Clin. Med., 2012; 29: S117-S121

\begin{abstract}
Coronary artery disease is the leading cause of death in the world. Stable angina pectoris is a discomfort in the chest or adjacent areas caused by effort. This review will focus on the medical and invasive treatment of chronic stable angina, with a focus in new strategies. The goal of treatment is to improve quality of life, decrease cardiovascular events and mortality. Risk stratification should be made for optimal therapeutic choices. Risk stratification hierarchy can be described as: Clinical evaluation, stres testings, left ventricular function and coronary angiography.
\end{abstract} J. Exp. Clin. Med., 2012; 29:S117-S121

\section{Giriş}

Koroner arter hastalığı tüm dünyada halen en önemli ölüm nedenlerinin başında gelmektedir. Yaş ile artmakla birlikte 45-74 yaş arası genel popülasyonda \% 0,1-20 arasında angina pektoris ortaya çıkmaktadır. Özellikle çoğu Avrupa ülkesinde bir milyon nüfus başına 20.000-40.000 kişide angina bulunduğu düşünülmektedir. Türkiye'de Erişkinlerde Kalp Hastalığı ve Risk Faktörleri Sıklığı Taraması (TEKHARF) çalışması verilerine göre ise ülkemizde koroner arter hastalığ1 (KAH) 49 yaş veya daha gençlerde \%2,3 iken, 50-59 yaş grubunda $\% 13,3,60-69$ yaş gurubunda $\% 21,6,70$ yaş ve üzerinde \%20 bulunmuştur (Onat ve ark., 1991).

\section{Tanım}

Angina pektoris göğüs, çene, omuz, sırt ve kolda rahat- sılık ya da ağrı hissiyle karakterize bir klinik sendrom olarak tanımlanmaktadır. Bu tanımlama angina pektorisin etiyolojisine bakılmaksızın semptomatik bir tanımlama olsa da klinik pratikte angina pektoris, sıklıkla miyokardiyal iskemi ile ilişkilidir. Daha az olarak özofagus, akciğer ve göğüs ön duvarı hastalıkları gibi kalp dışı nedenler ile de benzer semptomlar oluşabilmektedir. Angina pektorisin sahip olduğu özellikler ile etiyolojisi arasında ilişki kurmak mümkündür. Buna göre angina pektoris tipik, atipik ve nonkardiyak angina olarak isimlendirilebilir (Diamond, 1983) (Tablo 1) .

Genel olarak egzersiz ya da stres ile provoke olup istirahat ya da nitrat alımı ile rahatlayan angina kararlı angina pektoris olarak isimlendirilir. Buna karşın yeni başlangıçlı ağır angina pektoris (60 gün içerisinde), miyokart enfarktüsü sonrası angina ve akselere angina (4 hafta içerisinde) karar- 


\section{Tablo 1. Angina pektoris semptom kriterleri}

1. Tipik süre ve özellikte olmak kaydıyla substernal yerleşimli göğüs ağrisı,

2. Egzersiz veya emosyonel stres ile indüklenebilen göğüs ağrısı,

3. İstirahat veya nitrat tedavisi ile iyileşen göğüs ağrısı

Tipik angina (kesin): Kriterlerinin hepsinin varlığında,

Atipik angina (olası): Bu kriterlerin yalnız ikisinin varlığında,

Nonkardiyak göğüs ağrısı: Yalnızca bir tane kriterin olması veya hic birinin olmaması durumunda.

sızlık göstergeleridir. İstirahat anginası olmamasına rağmen bu özellikler kararlı angina pektoris tanımlaması içerisinde değerlendirilemez. (European Society of Cardiology, 2006).

\section{Fizyopatoloji}

Hücresel seviyede miyokardın oksijen talebindeki artış ya da miyokarda sunulan oksijen seviyesindeki azalma kardiyak anginanın sebebidir. Siklıkla koroner arterlerdeki darlık sonucunda oksijen sunumunun azalması sorumlu olsa da artmış kalp hızı, kontrolsüz hipertansiyon, artmış miyokardiyal kontraktilite gibi oksijen talebindeki anormal artışlar da anginaya yol açabilmektedir (Raab, 1962).

Miyokardiyal iskemi neticesinde oluşan laktik asidoz koroner sirkulasyona laktat, serotonin, bradikinin, histamin, reaktif oksijen ürünleri ve adenozin gibi medyatörlerin salınmasına yol açar. Miyokart hücreleri ve koroner damarlar etrafindaki miyelinsiz sinirlerin kemosensitif ve mekanoreseptif reseptörleri tarafindan algılanan bu medyatörler spinal kordun sıklıkla yedinci servikal vertebra ile dördüncü torakal vertebra arasındaki sempatik gangliona ulaşır. $\mathrm{Bu}$ anatomik özellik anginanın niçin göğüs, boyun, çene ve sol kolda hissedildiğini de açıklamaktadır (Fu ve Longhurst, 2005).

\section{Angina pektoris tanısı}

Angina pektoris tanısındaki altın anahtar öykünün dikkatli alınmasıdır. Hastanın semptomlarının süresi, arttıran ya da azaltan faktörlerin belirlenmesi ve de hastanın koroner arter hastalığı risk faktörlerinin ortaya konması tanıyı kolaylaştıracaktır. Buna karşın özellikle kadın hastalarda daha fazla olmakla beraber semptomların atipik olabileceği unutulmamalidır. Egzersiz dispnesi, terleme ve yorgunluk bazı hastalarda göğüs ağrısı olmaksızın iskemik kalp hastalığının semptomu olabilir. Angina eşdeğeri olarak kabul edilen bu semptomların da miyokardiyal iskemiyi tetikleyebilecek provokasyanlar ile ortaya çıkıp istirahat ya da nitrat alımı ile rahatlaması tanıda yardımcı olacaktır.

Fizik muayenede koroner arter hastalığının risk faktörleri olan dislipidemi, obezite ve hipertansiyonun bulguları görülebilir. İstirahat elektrokardiyografisi (EKG) ilk bakılması gereken testtir. Eski miyokart enfarktüsü ya da sol ventrikül hipertrofisi gibi risk göstergeleri dışında hastaların yarısından fazlasinda istirahat EKG'si normaldir. Bu nedenle EKG'nin normal olması koroner arter hastalığını dışlamaz. Laboratuvar testi olarak hastadaki koroner arter hastalığı risk faktörleri araştırılmalıdır. Bu amaçla lipit paneli ve açlık kan şekeri temel laboratuvar incelemeleridir.

Kararlı angina pektoris hastalarında iskemiyi göstermeye yönelik testler ise provokatif stres testlerini içerir. Stres testleri hem mevcut semptomların iskemik kökenli olduğunun hem de prognozun önemli bir göstergesidir. Bu amaçla egzersiz EKG'si ve stres perfüzyon sintigrafileri en s1k kul- lanılan testlerdir. Egzersiz EKG'sinin duyarlılığı ortalama \%68, özgüllüğü ise \%77 olarak bildirilmiştir (Fox ve ark., 2006). Stresle perfüzyon sintigrafisi egzersiz EKG'sinden fazla olarak iskeminin yeri ve yaygınlığı hakkında da bilgi vermektedir. Duyarlılık ve özgüllük oranları ise \%80-85 ve \%84-86 olarak bildirilmektedir (Fox ve ark., 2006). Ayrıca perfüzyon sintigrafileri egzersiz yapamayacak kisitlılıklar1 olan hastalarda farmakolojik stres ajanları ile birlikte de uygulanabilmektedir. Egzersiz stres ekokardiyografi de tan1sal amaçla uygulanan bir görüntüleme yöntemidir. İskemik miyokardın egzersize olan anormal yanıtının ortaya konması esasına dayanan bu incelemenin duyarlılık ve özgüllüğü s1rasiyla, \%80-85 ve \%84-86' dir (Fox ve ark., 2006). Teknik zorlukları nedeniyle stres ekokardiyografisi pratik kullanımda sık tercih edilmemektedir. Doku doppler ve strain görüntü yöntemlerinin kullanımı ile yakın zamanlarda daha sık araştırilmaktadır.

Kardiyak Bilgisayarlı tomografi (BT) ve Magnetik rezonans görüntüleme (MRG) anginası olan hastalarda koroner arter hastalığı ve iskeminin ortaya konması için kullanılabilmektedir. BT ile koroner kalsifikasyon skorlaması yapılması ve son zamanlarda daha popüler olan çok kesitli BT (ÇKBT) ile koroner arterlerin görüntülenmesi sağlanabilmektedir. Özellikle hastalık olasılığı düşük ve stres testlerinin tatmin edici olmadığı hastalarda ÇKBT ile görüntüleme önerilebilir. Kardiyak MRG ise stres ekokardiyografisine benzer olarak iskemik miyokardın stres ile ortaya çıkan anormal hareketlerinin gösterilmesi konusunda yararlı olabilir (European Society of Cardiology, 2006).

\section{Kararlı angina pektoris derecelendirmesi}

Kararlı angina pektoris şiddetine göre de derecelendirilebilir. Bu anginaya sebep olan hastalığın şiddeti, yaygınlığı, prognozu ve tedaviye alınan yanıtı değerlendirmek açısından yararlıdır. Anginanın şiddeti hastadan hastaya ya da aynı hastada farklı zamanlarda farklı seviyelerde olabilir. Günümüz pratiğinde en sık kullanılan sınıflama Kanada Kardiyovasküler Derneği'nin yaptığı sınıflamadır. Bu sınıflamaya göre kararlı angina şiddeti dört dereceye ayrılmıştır (Tablo 2).

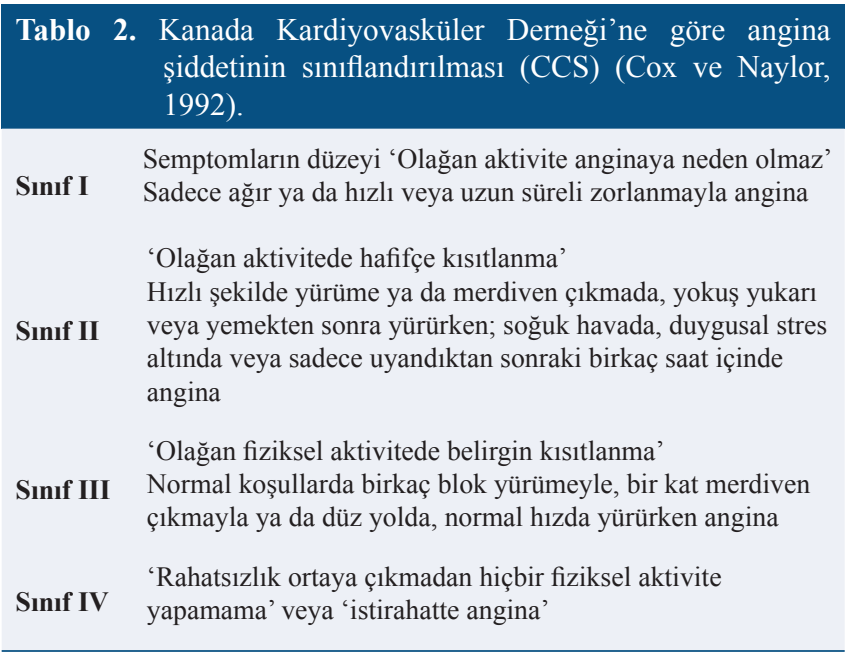

\section{Risk derecelendirmesi}

Hastaların tedavi seçenekleri belirlenirken amaç hastaların kardiyovasküler sağ kalım ve yaşam kalitelerini iyileş- 
tirmektir. Bu amaçla yaşam şekli değişikliğinden başlayarak cerrahi revaskülarizasyona kadar geniş bir tedavi alternatifi sunulabilir. Önemli olan ise progonozu en iyi etkileyebilecek en az invazif tedavinin seçilmesidir. Hastalarda kardiyovasküler olay geçirme riski arttıkça invazif tedavilerin sağladığı olumlu etki de artmaktadır. Günümüz kılavuzlarında kararlı angina pektoris için bir yıllık kardiyovasküler ölüm riski $\% 2$ nin üzerinde olduğu belirlenir ise hasta yüksek riskli, \%1' in altında düşük riskli ve \%1-2 ise orta düzeyde riskli olarak kabul edilmektedir. Hastalarda risk derecelendirmek için gerekli bilgi, klinik değerlendirme, stres testine yanıt, ventriküler işlevin nicel olarak değerlendirilmesi ve KAH yaygınlığından oluşan dört önemli bölüm içerir.

\section{Klinik değerlendirme}

Diyabet, hipertansiyon, metabolik sendrom, o siradaki sigara alışkanlığı ve yüksek total kolesterol, kararlı angina olan hastalarda veya koroner arter hastalığı saptanan diğer hasta gruplarında kötü prognoza işaret eder. İleri yaş, geçirilmiş Miyokart Enfarktüsü (ME), kalp yetersizliği semptom ve bulguları, anginanın şiddeti de dikkate alınması gereken önemli faktörlerdir (Hultgren ve ark., 1984; Califf ve ark., 1988).

Anginanın ortaya çıkma paterni, angina sıklığı ve istirahatte EKG anormallikleri, sağkalım ve ME geçirmeksizin sağkalım için bağımsız tahmin etmenleridir ve basit bir puanlama içerisinde kullanılarak bu risk derecesi rakamlaştırılmıştır (Hultgren ve ark., 1984). Bu puanlamaya göre nokturnal angina ve kararsız angina en yüksek puanlı anginalardır. İstirahat EKG'si tanısal değerlendirme açısından koroner arter hastaları için eşsiz bir araçtır. Kararlı angina hastalarında istirahat EKG'sinin önemli oranlarda normal olabileceği bilinmesine karşın EKG'de görülebilecek geçirilmiş ME, sol dal bloğu, sol anterior hemiblok, sol ventriküler hipertrofi, ikinci veya üçüncü derecede AV blok ya da atriyal fibrilasyon varlığında prognozun olumsuz göstergeleri olduğu da gösterilmiştir (European Society of Cardiology, 2006).

\section{Stres testleriyle risk değerlendirmesi}

$\mathrm{Bu}$ amaçla sıklıkla kullanılan testler egzersiz EKG'si, stresle perfüzyon sintigrafisi ve stres ekokardiyografisidir. Egzersiz EKG'si kullanımının pratikliği, verdiği önemli prognostik bilgiler nedeniyle günümüzde bu amaçla en sık kullanılan ve ilk tercih edilmesi gereken stres testidir. Egzersiz EKG'si aynı zamanda iskemi eşiği, iskemi boyutları, şiddeti ve işlevsel kapasiteyi de gösterir. Test sonuçları tek başına değil hastanın klinik bilgileri ile birleştirilerek değerlendirme yapılmalıdır. Bazı çalışmalardan elde edilen prognostik bilgiler birleştirilerek egzersiz testi için bir skorlama yöntemi geliştirilmiştir. Bu esasla geliştirilen Duke yürüme bandı puanı (Duke treadmill score; DTS) egzersiz süresi, ST değişikliği ve egzersiz sırasında anginayı değerlendiren bir ölçektir (Mark ve ark., 1987) (Tablo 3).Risk derecelendirmesi amacıyla kullanılan bir diğer test stres ekokardiyografisidir. Değerlendirene ait farklılıklar göstermesi dışında oldukça önemli bilgiler sağlamaktadır. Testin negatif sonuç verdiği hastalarda ölüm veya ME görülme olasılığı y1lda $<\% 0,5$ 'tir.

Stres perfüzyon sintigrafisi normal olan hastalarda da gelecek yılda $<\% 1$ ölüm ve ME oranı belirlenmektedir. Diğer taraftan anormal perfüzyon bulgularının da yüksek kardiyovasküler sonlanımlar ile ilişkisi ortaya konmuştur.
Tablo 3. Duke yürüme bandı puanlaması (Mark ve ark., 1987).

\begin{tabular}{lllll}
$\begin{array}{l}\text { Dakika olarak } \\
\text { egzersiz süresi }\end{array}$ & n & Risk & n toplam & $\begin{array}{l}\mathbf{1} \text { yıllık } \\
\text { mortalite }\end{array}$ \\
\hline mm ST çökmesi X5 & $-n$ & Düşük risk & $\geq 5$ & $\% 0,25$ \\
$\begin{array}{l}\text { Angina } \\
\text { (kısıtlayıcı değil X4) }\end{array}$ & $-n$ & Orta risik & $-10-4$ & $\% 1,25$ \\
$\begin{array}{l}\text { Angina (kısıtlayıcı } \\
\text { X8) }\end{array}$ & $-n$ & Yüksek risk & $\leq-11$ & $\% 5,25$ \\
\hline
\end{tabular}

Puanlamada dakika egzersiz süresi pozitif, diğer kriterler ise negatif puanlanır. Puanlanan rakamların(n) toplamına göre 1 yıllık mortalite ve risk derecelendirmesi yapılabilir.

\section{Ventrikül işlevinin değerlendirilmesi}

Koroner arter hastalığında uzun süreli prognoz için en iyi belirleyici sol ventrikül fonksiyonudur. İstirahat EF'sinin azalması ile mortalite artmaktadır. Koroner Arter Cerrahisi çalışması (CASS) verilerine göre 12 yıllık sağ kalım EF $>\% 50$ olan hastalarda \%73 iken, <\%35 olan hastalarda bu oran \%21 olarak bulunmuştur (Emond ve ark., 1994).

\section{Koroner arteriyografi}

Koroner damarların konvansiyonel anjiyografik yöntemler ile gösterilmesi koroner aterosklerozun doğası hakkında bilgi vermese de koroner darlıkların yerleşim yeri, şiddeti ve yaygınlığı koroner arter hastalığının prognozu ile ilgili oldukça kıymetli bilgiler sağlamaktadır. CASS' da çalışmasında koroner arterleri normal saptanan hastalarda 12 yıllık sağ kalım \%91'in üzerinde bulunmuştur (Emond ve ark., 1994). Buna karşın hesaplanan kardiyovasküler y1llık mortalite oranı $<\% 1$ saptanan hastalarda risk derecelendirmesi için koroner anjiyografi kullanımı büyük olasılıkla uygun değildir. Günümüzde kılavuzlar özellikle noninvazif testler ile yüksek riskli olduğu düşünülen hastalarda, medikal tedaviye rağmen şiddetli anginası devam eden hastalarda (CCS sınıf 3-4), major kalp dişı cerrahi geçirecek orta riskli hastalarda koroner anjiyografiyi sınıf I endikasyon ile önermektedir. Diğer taraftan noninvazif yöntemlerin tatmin edici sonuçlar vermediği hastalarda ve Perkutan Koroner Girişim (PKG) sonrası yüksek yeniden darlık gelişmesi beklenen hastalarda da sınıf IIa olarak önerilmektedir (Fox ve ark., 2006).

\section{Tedavi}

Kararlı angina pektoris hastasının tedavisinin amacı ölüm ve miyokart enfarktüsü olasılığını azaltmakla beraber semptomların en aza indirilmesi ya da tamamen ortadan kaldırılmasını içerir. Bu amaçla yaşam şekli değişikliği, ilaç tedavisi ve girişimsel tedavi seçenekleri kullanılabilir.

Hastalar koroner arter hastalığı hakkında bilgilendirilmelidirler. Hastaların sebze, meyve, balık ve kümes hayvanlarından zengin bir Akdeniz diyeti benimsemesi tavsiye edilmelidir. Sigara bırakılmalı ve aşırı alkol tüketiminin de zararlı olduğu belirtilmelidir. Hipertrigliseridemiyi ve ME sonrası ölümü azalttığı kanıtlanmış Omega-3'den zengin balık yağlarının alınması tavsiye edilebilir.

Fiziksel aktivitenin egzersiz toleransını $\operatorname{artırdığ~}$ ve semptomları azalttığı gösterilmiştir. Vücut ağırlığı, kan yağları, kan basıncı, glukoz toleransı ve insüline duyarlılık üzerinde olumlu etkileri bulunduğundan, hastanın sınırları içinde yer alacak şekilde teşvik edilmelidir.

Diyabet, hipertansiyon ve dislipidemi gibi ateroskleroz sürecini olumsuz etkilediği iyi bilinen hastalıklar da optimal 
şekilde tedavi edilmeye çalışılmalıdır. Koroner arter hastalığ ve diyabet gibi yüksek risk faktörleri olan hipertansif hastalarda hedeflenen kan basıncı değerinin daha düşük olmaS1 gerekebileceği de unutulmamalıdır. Bu hastalarda 140/90 $\mathrm{mmHg}$ altı yerine $130 / 80 \mathrm{mmHg}$ altı değerlerin hedeflenmesi daha akıllıca görünmektedir (Mancia ve ark., 2007).

\section{Farmakolojik tedavi}

Kararlı angina pektoris tedavisinde kullanılan farmakolojik ajanları hastalığın prognozuna yönelik olanlar ve anginal semptomları azaltmaya yönelik olanlar olarak sınıflamak mümkündür.

\section{Antitrombositer ilaçlar}

Düşük dozda aspirin bu amaçla kullanılan en önemli ilaçlardandır. COX-1 ve dolayısıyla tromboxan üretimini geri dönüşsüz olarak inhibe eder. Optimum etkinin 75-150 mg/gün dozunda elde edildiği görülmüştür (Antithrombotic Trialists' Collaboration, 2002). Gastrointestinal yan etkileri doz ile birlikte artabilir. Antitrombositer dozlarda kafa içi kanamayı arttırdığına ilişkin kanıt yoktur.

Klopidogrel ve tiklopidin yarışmacı olmayan ADP reseptör antagonisti antitrombositer ilaçlardır. ME geçirmiş, inme geçirmiş veya periferik arter hastalığı $(\mathrm{PAH})$ olan hastalarda $325 \mathrm{mg}$ aspirine göre klopidogrel $75 \mathrm{mg} /$ gün kardiyovasküler komplikasyonları önlemede hafifçe daha etkili bulunmuştur (CAPRIE Steering Committee, 1996). Özellikle stent uygulanan hastalarda tromboz riskini önlemek için aspirine ek olarak ya da aspirini tolere edemeyen hastalarda aspirin yerine tercih edilebilir.

\section{Lipit düșürücü ilaçlar}

Primer ve sekonder koruma çalışmaları aterosklerotik kalp hastalığının tedavisinde statinlerin sağ kalım üzerine olan olumlu etkilerini kanıtlamıştır (Reiner ve ark., 2011). Diğer taraftan PKG öncesi verilen statin tedavisinin PKG'e bağlı komplikasyonları azalttığı da gösterilmiştir. Kolesterol düzeyi normal olan hastalarda dahi gösterilmiş olan faydalı etkiler nedeniyle koroner arter hastalarında statin tedavisinin sadece dislipidemisi olan hastalar ile sınırlı olmaması gerektiği söylenebilir. Statin tedavisinde kullanılması gereken doz en az morbidite ve mortaliteyi azalttığı gösterilmiş olan dozlar kadardır. Hedeflenen LDL seviyesi yüksek riskli hastalarda olduğu gibi $70 \mathrm{mg} / \mathrm{dl}$ 'nin altında olmalıdır (Reiner ve ark., 2011). Yüksek dozlarda statin kullanımı karaciğer hasarının enzimatik düzeylerinde artma ile ilişkili bulunurken, doza bağlı olarak miyalji sıklığında belirgin artış görülmemiştir.

\section{Anjiyotensin dönüştürücü enzim (ACE) inhibitörleri}

ACE inhibitörleri ME sonrası ve kalp yetersizliği olan hastalarda iyi araştırılmış ve olumlu prognostik etkileri gösterilmiştir. Bunun yanında Heart Outcomes Prevention Evaluation (HOPE) ve European Trial On Reduction Of Cardiac Events With Perindopril In Stable Coronary Artery Disease (EUROPE) çalışmalarıyla da yüksek riskli hastalarda kullanılan ramipril ve perindoprilin birleşik son noktaları yaklaşık $\% 20$ 'ler düzeyinde azalttığı da gösterilmiştir (Yusuf ve ark., 2000; Fox, 2003). Ancak görece daha düşük riskli hastalarda bu fayda görülemeyebilir. Özellikle eşzamanlı hipertansiyon, diyabet, kalp yetersizliği, asemptomatik sol ventrikül işlev bozukluğu ve geçirilmiş ME olan kararlı angina pektoris has- talarının tedavisinde ACE inhibitörlerinin düşünülmesi uygundur.

\section{Beta blokerler}

ME sonrası hastalarda kullanıldığında beta blokerlerin kardiyovasküler mortaliteyi \%30 düzeyinde azalttığı gösterilmiştir. Kararlı angina pektoris hastalarında da bu faydanın olacağı düşünülmekteyse de henüz bu durum randomize çalışmalar ile kanıtlanmamıştır. Diğer önemli bir nokta ise intrensek sempatomimetik aktivitesi olan beta blokerlerin bu amaçla kullanımının iyi bir seçenek olamayabileceğini düşündüren verilerin olmasıdır.

Kalp hızının, kontraktilitenin ve sol ventrikül duvar geriliminin azalması nedeniyle miyokardın oksijen tüketiminin azalması, diğer yandan diyastolün uzayarak oksijen sunumunun artması beta blokerlerin temel antiiskemik etkilerini oluşturmaktadır. Soğuk ekstremiteler, semptomatik bradikardi, bronkokonstriksiyon, depresyon bulgularında artma ve erektil disfonksiyon gibi yan etkiler tedavi sürecinde karşılaşılabilir.

\section{Kalsiyum kanal blokerleri}

The Danish Verapamil Infarction Trial II (DAVIT II) çalışmasında verapamil ve Multicenter Diltiazem Postinfarction Trial (MDPIT) çalışmasında kalp yetersizliği bulgusu olmayan bir hasta alt grubunun analizinde diltizem için gösterilmiş olduğu gibi, kalp hızını düşüren kalsiyum kanal blokerleri de (KKB'ler) ME sonrası hastalarda prognozu olumlu yönde etkileyebilmektedir (DAVIT II, 1990; MDPIT, 1988). Buna karşın kısa etkili nifedipinin olumsuz etkileri olabileceği görülmüştür. Sonuç olarak komplikasyonsuz kararlı angina hastalarının tedavisinde beta blokeri tolere edemeyen hastalarda alternatif olarak kullanılabilmektedir.

Diltiazem ve verapamil gibi kalp hızını azaltan kalsiyum kanal blokerleri beta blokerlere benzer bir etki ile anginal semptonları da azaltmaktadır. Diğer taraftan vazoselektif blokerlerin (amlodipin, nifedipin, felodipin) kullanımının refleks sempatomimetik etkileri kardiyodepresif etkilerini zamanla baskılayabilir. Buna karşın Nissen ve ark. (2004) tarafından amlodipinin anginal atakları azalttı̆̆ gösterilmiştir. Baş ağrıs1, yüzde k1zarma, ayak bileğinde ödem gibi vazodilatör yan etkileri yanında özellikle verapamil konstipasyona yol açabilir.

\section{Nitratlar}

Kısa etkili nitratlar venodilatasyon ve kalp içi basıncı azaltarak subendokardiyal perfüzyonu olumlu etkilerler. Baş ağrısı, postural hipotansiyon gibi yan etkileri hakkında hasta bilgilendirilmelidir. Uzun etkili nitratlar da benzer etkileriyle kullanılabilir. Buna karşın nitrat tedavisinin koroner arter hastalığında prognostik yararı gösterilememiştir. Nitrat tedavisi verilen hastalarda dikkat edilmesi gereken bir nokta da tolerans gelişme riskinden dolayı gün içerisinde nitratsız dönemler olması gerektiğidir.

\section{Sinüs düğg̈mü inhibitörleri}

İvabradin diyastolik depolarizasyonun major belirleyicisi olan If kanal inhibitörüdür. Sinüs dügümünün hızını azaltarak etki gösterir ve sinüs ritminde olmayan hastalarda kullanımı endike değildir. Anginalı hastalardaki egzersiz toleransını ve yürüme mesafesini düzelttiği gösterilmiştir (Fox ve ark., 
2009). Yakın zamanda yapılan çalışmalar; Werdan ve ark. (2012) özellikle ivabradinin beta blokere alternatif olarak kullanımı dışında beta blokere ilave olarak kullanımının da oldukça etkili ve avantajlı olduğunu düşündürmektedir. KKB ve beta-bloker (BB) ajanlar ile karşılaştırıldığında kardiyak inotropi üzerine depresif etkilerinin olmaması bazı avantajlar sağlayabilir.

Metabolik yoldan etki gösteren ilaçlar, yağ asitlerine göre glukoz metabolizmasını artırarak iskemiye karşı korur. Hem trimetazidin hem de ranolazinin antianginal etkinliği bulunduğu gösterilmiş bu grup ilaçlardandır (Marzilli ve Klein, 2003).

\section{Revaskülarizasyon}

Kararlı angina hastaları için uygulanan miyokardiyal reperfüzyon seçenekleri daha çok farmakalojik tedavinin sağkalım açısından ya da semptomların kontrolü açısından yetersiz olduğu düşünülen hastalar için endikedir. Yakın zamanda

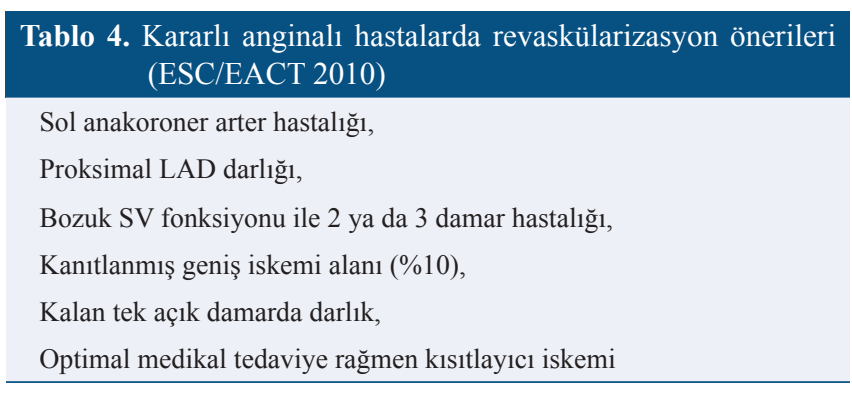

Avrupa derneklerinin katkılarıyla hazırlanan revaskülarizasyon kılavuzunda özellikle geniş iskemi alanlarının olduğu düşünülen durumlar ve medikal tedaviye rağmen kısıtlayıı1 iskeminin devam ettiği anginalı hastalarda revaskülarizasyon önerilmektedir (Wijns ve ark., 2010) (Tablo 4). Revaskülarizasyonun şekli ise koroner hastalığın yaygınlığı, lokalizasyonu ve PKG'ye uygunluğuna göre cerrahi ya da perkutan olabilmektedir.

\section{KAYNAKLAR}

Antithrombotic Trialists' Collaboration, 2002. Collaborative meta-analysis of randomised trials of antiplatelet therapy for prevention of death, myocardial infarction, and stroke in high risk patients. B.M.J. 324, 71-86.

Califf, R.M., Mark, D.B., Harrell, F.E., Jr Hlatky, M.A., Lee, K.L., Rosati, R.A., Pryor, D.B., 1988. Importance of clinical measures of ischemia in the prognosis of patients with documented coronary artery disease. J. Am. Coll. Cardiol. 11, 20-26.

C.A.P.R.I.E. Steering Committee, 1996. A randomised, blinded, trial of clopidogrel versus aspirin in patients at risk of ischaemic events (C.A.P.R.I.E.). Lancet. 348, 1329-1339.

Cox, J., Naylor, C.D., 1992. The Canadian Cardiovascular Society grading scale for angina pectoris: Is it time for refinements. Ann. Intern. Med. $117,677-683$.

Diamond, A.G., 1983. A clinically relevant classification of chest discomfort. J. Am. Coll. Cardiol. 1, 574-575.

Emond, M., Mock, M.B., Davis, K.B., Fisher, L.D., Holmes, D.R., Jr Chaitman, B.R., Kaiser, G.C., Alderman, E., Killip, T., 1994. III. Long-term survival of medically treated patients in the coronary artery surgery study (C.A.S.S.) registry. Circulation. 90, 2645-2657.

ESC/EAS Guidelines for the management of dyslipidaemias, 2011. Eur. Heart J. 32, 1769-1818.

European Society of Cardiology, 2006. Guidelines on the management of stable angina pectoris. Eur. Heart J. 27, 1341-1381.

European Society of Cardiology and the European Association for Cardio-Thoracic Surgery Guidelines on myocardial revascularization, 2010. Eur. Heart J. 31, 2501-2555.

European Society of Hypertension of the European Society of Cardiology. 2007 Guidelines for the management of arterial hypertension. Eur. Heart J. 28, 1462-1536.

Fox, K., Ford, I., Steg, P.G., Tendera, M., Robertson, M., Ferrari, R., 2009. Beautiful investigators. Relationship between ivabradine treatment and cardiovascular outcomes in patients with stable coronary artery disease and left ventricular systolic dysfunction with limiting angina: A subgroup analysis of the randomized, controlled beautiful trial. Eur. Heart J. 30, 2337-2345.

Fox, M.K., 2003. Efficacy of perindopril in reduction of cardiovascular events among patients with stable coronary artery disease: Randomised, double-blind, placebo-controlled, multicentre trial. Lancet. 362, 782-788.

Fu, L.W., Longhurst, J.C., 2005. Interactions between histamine and bradykinin in stimulation of ischaemically sensitive cardiac afferents in felines. J. Physiol. 565, 1007.

Hultgren, H.N., Peduzzi, P., 1984. Relation of severity of symptoms to prognosis in stable angina pectoris. Am. J. Cardiol. 54, 988-993.

Mark, D.B., Hlatky, M.A., Harrell, F.E., Jr Lee, K.L., Califf, R.M., Pryor, D.B., 1987. Exercise treadmill score for predicting prognosis in coronary artery disease. Ann. Intern. Med. 106, 793-800.

Marzilli, M., Klein, W.W., 2003. Efficacy and tolerability of trimetazidine in stable angina: A meta-analysis of randomized, double-blind, controlled trials. Coron. Artery Dis. 14, 171-179.

Nissen, S.E., Tuzcu, E.M., Libby, P., Thompson, P.D., Ghali, M., Garza, D., Berman, L., Shi, H., Buebendorf, E., Topol, E.J., 2004. Effect of antihypertensive agents on cardiovascular events in patients with coronary disease and normal blood pressure: The camelot study: A randomized controlled trial. JAMA. 292, 2217-2225.

Onat, A., Şurdum-Avc1, G., Şenocak, M., Örnek, E.,Gözükara, Y., Karaaslan, Y., Özışık, U., İşler, M., Tabak, F., Özcan, R., 1991. Türkiye'de erişkinlerde kalp hastalığı ve risk faktörleri sıklığı taraması: 3. Kalp hastalıkları prevalansı. Türk Kardiyol. Dern. Arş. 19, 26-33.

Raab, W., 1962. The sympathogenic biochemical trigger mechanism of angina pectoris: Its therapeutic suppression and long-term prevention. Am. J. Cardiol. 9, 576-590.

The Danish verapamil infarction trial II-DAVIT II, 1990. Effect of verapamil on mortality and major events after acute myocardial infarction. Am. J. Cardiol. 66, 779-785.

The multicenter diltiazem postinfarction trial research group-MDPIT. 1988. The effect of diltiazem on mortality and reinfarction after myocardial infarction. N. Engl. J. Med. 319, 385-392.

Werdan, K., Ebelt, H., Nuding, S., Höpfner, F., Hack, G., Müller-Werdan, U., 2012. Ivabradine in combination with beta-blocker improve symptoms and quality of life in patients with stable angina pectoris: Results from the ADDITIONS study. Clin. Res. Cardiol. 101, 365-373.

Yusuf, S., Sleight, P., Pogue, J., Bosch, J., Davies, R., Dagenais, G., 2000. Effects of an angiotensin-converting-enzyme inhibitor, ramipril, on cardiovascular events in high-risk patients. The heart outcomes prevention evaluation study investigators. N. Engl. J. Med. 342, 145-153. 